\title{
A Influência dos Stakeholders no Ambiente Estratégico de uma CoOperativa de CRÉdito: efeitos dA MUNIficênCIA
}

\author{
The Influence of Stakeholders in a Strategic Environment Credit \\ Cooperative: effects of munificence
}

Yeda Maria Pereira Pavão

Professora do Curso de Graduação em Administração, Faculdade Estadual de Ciências e Letras Campo Mourão - Campo Mourão PR, Brasil.E-mail: yedapavao@gmail.com

\section{Michael Samir Dalfovo}

Doutorando do Programa de Pós-Graduação em Administração, Universidade do Vale do Itajaí - Blumenau - SC, Brasil. E-mail: msdalfovo@gmail.com

\section{Maria Andréa Rocha Escobar}

Professora do Programa de Pós-Graduação em Contabilidade e Controladoria, Universidade Federal do Amazonas - Manaus - AM, Brasil.E-mail: andrea.ufam@hotmail.com

\section{Carlos Ricardo Rossetto}

Professor do Programa de Pós-Graduação em Administração e Turismo, Universidade do Vale do Itajaí - Biguaçu - SC, Brasil. E-mail: rossetto@univali.br

\section{Resumo}

O objetivo deste artigo é analisar a relação entre as estratégias de influência dos stakeholders, o ambiente munificente, e a capacidade de administração dos stakeholders na Viacredi Cooperativa de Crédito de Blumenau / SC. O principal parâmetro teórico e analítico foi obtido nos estudos efetuados por Freeman (1984), Frooman (1999), e Castrogiovanni (1991). A análise documental e de conteúdo foram realizadas por meio de procedimento descritivo-qualitativo. A unidade de análise foi o nível estratégico (Presidente), tático e operacional. Os resultados obtidos apontam para a comunidade, cooperados, funcionários, instituições financeiras e governo como sendo os stakeholders primários da Viacredi. Outro resultado foi à preocupação da gestão em considerar o ambiente, seja interno ou externo, para a tomada de decisão, visto o ambiente ser identificado como complexo e munificente em termos de abundância de recursos. Conclui-se que há uma relação de interdependência entre os agentes envolvidos no ambiente organizacional da Viacredi.

Palavras-chave: Stakeholders. Ambiente Estratégico. Munificência.

\section{Abstract}

The objective of this paper is to analyze the relationship between the stakeholders influence strategies, the munificent environment, and the stakeholders management capability of Viacredi Cooperativa de Crédito de Blumenal / SC. The main theoretical and analytical parameter was obtained from the studies made by Freeman (1984), Frooman (1999) and Castrogiovanni (1991). The document and content analysis were made through descriptive-qualitative procedure. The unit of analysis was the strategic level (President), tactical and operational. The obtained results point to the comunity, members, employees, financial institutions and government being the primary stakeholders of Viacredi. Another result was the concern of the management in considering the environment, whether internal or external, for decision making, because the environment is identified as complex and munificent in therms of resource abundance. We conclude that there is a relationship of interdependence between the agents involved in the organizational environment of Viacredi.

Key words: Stakeholders. Strategic Environment. Munificence. 


\section{INTRODUÇÃo}

Na década de 1980, o termo stakeholders passou a ser discutido principalmente por Freeman (1984) considerado por autores (DONALDSON; PRESTON, 1995; MITCHELL, AGLE; WOOD, 1997) como o precursor do assunto. Dessa forma, estudos preconizados por Freeman (1984) apresentaram a historicidade que envolvia o termo. $\mathrm{O}$ autor ressaltou que a ideia teve início com: Adam Smith (1759), Berle e Means (1932) e Bernard (1938). O autor acrescenta que, a lista dos participantes incluía originalmente acionistas, empregados, clientes, fornecedores, credores e a sociedade. Nesse sentido, Frooman (1999) contribui com o avanço e disseminação da teoria, ao agregar aspectos sobre o grau de influência dos stakeholders na firma, ou ainda, nos estudos de Castrogiovanni (1991), ao abordar exclusivamente sobre o ambiente munificente com seus recursos abundantes e/ou escassos. Existem dois aspectos preponderantes relacionados à abundância $e$ a escassez de recursos. A abundância dos recursos se relaciona diretamente a sobrevivência da organização e a perseguirem suas metas além da sobrevivência. Assim, quando os recursos se tornam escassos, ocorre intensificação da competição, e consequentemente afeta de forma negativa a lucratividade da empresa, causando mudanças internamente e no comportamento dos membros da organização. (CASTROGIOVANNI, 1991)

Por outro lado, Sharfman e Dean Jr. (1991) retomam os autores precursores da mensuração do ambiente organizacional e os categoriza de acordo com a classificação dada pelos autores que considerou em sua fala como: "major works environments" (SHARFMAN; DEAN JR., 1991, p. 684). A categorização dada corresponde à complexidade, ao dinamismo e à estabilidade e à disponibilidade de recursos.

Em outra vertente teórica, os estudos que permeiam a teoria dos stakeholders também continuam cada vez mais presentes na literatura acadêmica $e$ são aplicados e replicados em distintas pesquisas. Por exemplo, os autores Donaldson e Preston (1995) ao examinarem os conceitos, implicações e efeitos relacionados à teoria dos stakeholder nas corporações. Elias, Cavana e Jackson (2002) fazem uma revisão na teoria dos stakeholders com vistas à aplicação de um projeto de P\&D. Já Philipps, Freeman e Wicks (2003) evidenciam o que não é teoria dos stakeholders e revelam que o termo significa coisas diferentes para pessoas diferentes e, portanto, evoca o elogio ou o desprezo de uma grande variedade de acadêmicos e de profissionais. Nos estudos de Shopshire e Hillmann (2007), os autores buscam explicar porque as empresas teriam uma experiência significativa na gestão dos stakeholders.

Relevante contribuição também é encontrada no trabalho dos autores Agle et al. (2008) ao retomarem diversos estudos que denominam como Dialogue: Toward Superior Stakeholder Theory, sendo a questão principal abordada por eles é de que agora não é se, mas como a teoria dos stakeholders enfrentará os desafios do seu sucesso.

A discussão da teoria dos stakeholders também se manifestou no trabalho de Rueda-Manzanares, Aragón-Correa e Sharma (2008) no qual os autores associam essa teoria com a dimensão do ambiente complexo, incerto e munificente, trilogia esta preconizada por Dess e Beard (1984). Porém, com a denominação complexidade, dinamismo e munificência.

No contexto brasileiro, os autores Hoffmann, Procopiak e Rossetto (2008) também fornecem relevantes contribuições a esta pesquisa, por incluírem nos seus estudos a abrangência da teoria sobre stakeholders, ao evidenciarem a ótica de sua identificação, além de analisarem os graus e as estratégias de influência. Nessa dimensão ambiental, organizações cooperativas também foram alvos de estudos como nos estudos de Ferreira, Gonçalves e Braga (2007), que buscarem investigar o desempenho das Cooperativas de Economia e Crédito Mútuo de Minas Gerais, quanto à eficiência e o seu papel de desintermediação financeira entre os seus membros associados, contudo, não se referiram à teoria dos stakeholders. Esses autores apresentam importante referência a esta pesquisa, ao se reportarem a World Council of Crédits Unions (WOCCU), ou ao Conselho Mundial de Cooperativas de Crédito (CMCC). Como informação adicional, justifica-se que O CMCC está sediado em Madison, Wisconsin nos EUA, e foi constituída em $1^{\circ}$ de janeiro de 1971, e é uma associação comercial global e agência de fomento para as cooperativas de crédito atuante em 97 países, dentre eles o Brasil (CMCC, 2010). Para o CMCC (2010), a cooperativa de crédito baseia-se no tripé sustentabilidade, igualdade e escolha. Dentre os seus preceitos, ressalta-se que as cooperativas de crédito 
existem para servir os seus membros e comunidades e diferencia-se dos Bancos principalmente pela sua estrutura, ou ainda, não possui fins lucrativos. Enfim, verifica-se que autores continuam a encontrar na teoria dos stakeholders associações, ou ainda, respostas para suas pesquisas direcionadas para a análise entre empresa $e$ as pessoas com seus distintos recursos, mas que se fazem necessários para a sua existência.

Dessa forma, a questão principal a ser respondida neste estudo é: Qual a relação entre as estratégias de influência dos stakeholders, o ambiente munificente $e$ a capacidade de administração dos stakeholders na Viacredi Cooperativa de Crédito em Blumenau/SC?

O objetivo principal culmina em analisar a relação entre as estratégias de influência dos stakeholders, os efeitos moderadores do ambiente munificente e a capacidade de administração dos stakeholders em uma cooperativa de crédito, antes e durante a implantação do Planejamento Estratégico. Para tanto, será necessário analisar as ações estratégicas da empresa delimitadas no planejamento estratégico (PE) da empresa quanto a cinco campos: (a) mercadológico; (b) econômico-financeiro; (c) desenvolvimento econômico e social; (d) processos internos; (e) patrimônio humano e cultura organizacional, na percepção de seus dirigentes. Nesse ínterim, a investigação especificamente será desenvolvida a partir da metodologia desenvolvida por Freeman (1984) sobre os três níveis de análise que deverão ser utilizados para a compreensão dos processos que uma organização precisa para o gerenciamento dos seus stakeholders (racional, processo e transacional); das tipologias de Frooman (1999) acerca das estratégias de influências dos stakeholders (grau de dependência entre os stakeholders e a firma); e Castrogiovanni (1991) quanto ao ambiente munificente (grau de escassez ou abundância de recursos). Assim, nossa contribuição neste estudo, é desenvolver um construto teórico ao estudar a relação entre as estratégias de influências dos stakeholders, o ambiente munificente e a capacidade de administração dos stakeholders em uma empresa do segmento cooperativo atuante no ramo financeiro, especificamente a Viacredi em Blumenau/SC. Para tanto, apresenta-se a seguir, além desse item, o aporte teórico necessário para tal compreensão e que possa desencadear futuras pesquisas que envolvam essa temática, além de evidenciar os stakeholders e o ambiente organizacional a partir dos autores precur- sores sobre os respectivos assuntos. Na próxima seção serão apresentados o método e os procedimentos da pesquisa, seguida da descrição e da análise dos dados em que se mostram os resultados do estudo empírico, obtidos com os dados primários e os secundários. Por último, serão apresentadas as considerações finais do trabalho, assim como as recomendações que poderão ser realizadas em outras pesquisas.

\section{Teoria dos Stakeholders}

A ideia inicial do termo stakeholder surgiu pela primeira vez na literatura de gestão em 1963, em um memorando interno da Stanford Research Institute (SRI), referindo-se "[...] aqueles grupos sem cujo apoio a organização deixaria de existir." (FREEMAN, 1984, p. 32). Entretanto, um dos conceitos seminais apontados por alguns autores (DONALDSON; PRESTON, 1995; MITCHELL, AGLE; WOOD, 1997; ROWLEY, 1997) para a definição do termo stakeholders como uma visão mais abrangente na literatura é designado pelo trabalho do próprio Freeman (1984) como: qualquer grupo ou indivíduo que afeta ou é afetado pelo alcance dos objetivos da organização. O autor ainda acrescenta que os stakeholders são grupos que têm direitos legitimados sobre a organização. No entanto, existem outras definições de caráter menos abrangente como a de Clarkson (1995), segundo o qual os stakeholders se diferenciam em primários e secundários. Clarkson (1995) descreve que sem uma participação contínua dos stakeholders primários a organização não conseguiria sobreviver, são eles: acionistas, investidores, empregados, fornecedores, clientes e governo, por haver um alto grau de interdependência entre a empresa e os mesmos. E aos stakeholders secundários o autor descreve algumas características a esse grupo, quais sejam: aqueles que influenciam ou afetam, ou são influenciados ou afetados pela organização; não realizam operações com mesma; não são essenciais a sua sobrevivência; e posuem capacidade de.mobilizar a opinião pública de forma favorável ou não. Ressalta ainda, que embora não diga respeito às atividades vitais para sobrevivência da organização, a negligência das relações secundárias por parte dos gestores pode prejudicar o funcionamento da empresa. 
Outra contribuição a este trabalho é dada por Donaldson e Preston (1995) ao abordarem a teoria dos stakeholder, dividindo-a em três dimensões: descritivo/empírica, instrumental e normativa. Os autores discorrem que é descritiva, por buscar compreender e explicar as características e comportamentos da organização, nesta dimensão, a teoria dos stakeholders tem sido utilizada para caracterizar a natureza da empresa, e evidenciar como os gestores pensam sobre gerenciamento e suas estratégias de gestão. Já a dimensão instrumental examina a influência dos stakeholders por meio da análise da relação entre os stakeholders e os objetivos da organização. Eà dimensão normativa, visa interpretar a função da organização, "[...] incluindo a identificação da moral ou orientação filosófica para a operação e gerenciamento das organizações". (DONALDSON; PRESTON, 1995, p. 65)

Sob outro prisma, Mitchell, Agle e Wood (1995) buscaram identificar quais os stakeholders seriam relevantes para a organização, e para esse feito, apresentaram uma proposta de classificação dos stakeholders, embasada em três atributos: poder, legitimidade e urgência. Para o primeiro atributo, a organização se utiliza do poder de o stakeholders influenciar a organização; a legitimidade é uma percepção generalizada, construída a partir de um sistema de normas, de valores, de crenças e de definições, intrínsecos nos indivíduos, na organização e na sociedade. A urgência é o grau com o qual os stakeholders reivindicam atenção. Nas palavras dos autores, o intuito em classificar os stakeholders tem relação com a identificação de quais grupos de stakeholders a organização deveria levar em consideração para o direcionamento de suas estratégias e tomada de decisão.

Já a discussão de como cada stakeholders pode influenciar as organizações foi desenvolvida por Frooman (1999) que contribuiu com o avanço e a disseminação da teoria, enfatizando que, nas pesquisas sobre a identificação dos stakeholders, existem três questões gerais a serem explicadas: quem eles são (atributos dos stakeholders), o que eles querem (finalidades dos stakeholders) e como eles estão agindo para atingir os objetivos (métodos utilizados pelos stakeholders). Para esse autor, além dessas questões citadas, há mais duas abordagens que devem ser levadas em consideração na análise dos stakeholders, e que auxilia no entendimento de como eles influenciam na formação de estratégias: (i) quais são os diferentes tipos de estratégias utilizadas pelos stakeholders para influenciar a organização; (ii) quais são os fatores determinantes na escolha. Esse mesmo autor apresenta um modelo para análise das estratégias de influência dos stakeholders, no qual combina os conceitos da teoria dos stakeholders com os conceitos da dependência de recursos; e o propósito de identificar que tipo de influência estratégica pode ser evidenciado, a partir da relação entre a organização e os stakeholders, na busca pelos recursos que estes últimos têm a oferecer. Ainda, segundo o autor, existem quatro tipos de estratégias de influência dos stakeholders sobre a organização: retenção direta e indireta; e uso direto e indireto. Além disso, o autor ressalta quatro tipos de relações sobre recursos, como: poder do stakeholders; alta dependência; baixa dependência; e poder da firma. Conforme pode ser visualizado no Quadro 1, há a relação de dependência da organização ao stakeholder e as possíveis estratégias de influência exercidas.

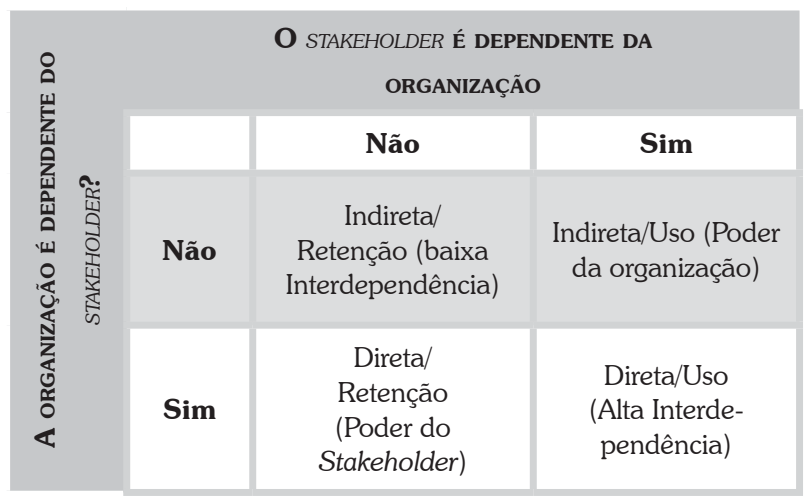

Quadro 1: Relação de dependência do stakeholder e da organização

Fonte: Adaptado de Frooman (1999)

No tocante à interpretação dessas relações, Frooman (1999) discorre que, quando há baixo nível de dependência da organização em relação ao stakeholder, significa que o stakeholder passa a utilizar estratégias de influência indireta e de retenção de recursos. E, quando há alto nível de dependência, o stakeholder utiliza estratégias diretas e de uso. Quando o relacionamento é marcado pelo poder da organização, o stakeholder utilizará uma estratégia de influência indireta e de uso. Ao contrário da última proposta na qual o stakeholder utiliza a influência direta de retenção de recursos. Fica evidente que a organização sofre influência de diversos e diferentes stakeholders, conforme pode ser verifica- 
do na interpretação dada pelo autor (Quadro 1). No entanto, o ambiente organizacional também pode ser bastante condicionado por fatores ambientais.

\section{Ambiente Organizacional}

Há décadas encontra-se na literatura acadêmica teóricos como Chandler (1962), Emery e Trist (1965), Lawrence e Lorsch (1967), Ducan (1972), Pfeffer e Salancik (1978), Aldrich (1979) e Hall (1984) que corroboram com a relevância das inter-relações entre a organização e o ambiente. Dentre os autores que procuraram o discernimento da dimensão dessas relações e o grau de influência que se estabelece entre elas, podem ser encontrados estudos que divergem quanto ao entendimento sobre o ambiente, se ele é constituído por elementos explícitos, objetivo ou de natureza concreta (DESS; BEARD, 1984); ou se caracteriza por um fluxo de informações externas para as organizações; interpretados e legitimados pela crença dos atores organizacionais (WEICK, 1979). Contudo, pesquisadores, que assumem a hipótese da existência do ambiente objetivo e de que é a percepção dos gestores sobre esse ambiente que determina o comportamento das organizações, tentaram aprofundar o conhecimento sobre o processo de formulação e de legitimação dessas teorias. (BATAGLIA, 2006)

De acordo com Sharfman e Dean Jr. (1991), ao relacionar as dimensões da realidade objetiva $e$ perceptiva, apontam-se as seguintes características: (i) a incerteza na tomada de decisão (LAWERENCE; LORSCH, 1967; DUNCAN, 1972); (ii) as condições ambientais e a percepção da incerteza (DUNCAN, 1972; TOSI; ALDAG; STOREY, 1973); (iii) o ambiente como fonte de recursos (THOMPSON, 1967; PFEFFER; SALANCIK, 1978); (iv) e o ambiente como fonte de variação da forma organizacional (EMERY; TRIST, 1965; HANNAN; FREEMAN, 1977; ALDRICH, 1979). Para Harris (2004) ainda há pouca concordância a respeito de como às dimensões do ambiente poderiam ser mensuradas.

Com base no interacionismo simbólico e com uma visão cognitiva, Weick (1979) argumenta que as organizações conhecem seu ambiente apenas a partir das percepções de seus gestores. Miles, Snow e Pferffer (1974) convergem com essa concepção por sugeriram que as empresas respondem ao que percebem, e que os sucessos despercebidos não afetam suas ações e decisões. Assim, os ambientes não são certos ou incertos por si mesmos, e sim que são percebidos de maneira diferente pelos tomadores de decisão. Para Aldrich (1979), a partir de uma vasta literatura precedente a respeito de dimensões utilizadas para caracterização do ambiente organizacional objetivo, avançou no campo teórico, desenvolvendo uma tipologia para as dimensões ambientais sendo categorizadas estas em seis: (i) concentração geográfica, (ii) heterogeneidade, (iii) estabilidade, (iv) turbulência (imprevisibilidade baseada na interconexão ambiental), (v) capacidade (disponibilidade de recursos) e (vi) consenso de domínio (competição pelos recursos), pautado na teoria ecológica e na dependência de recursos. Outra vertente sobre o ambiente organizacional e sua mensuração, foi tratada por Sharfman e Dean Jr. (1991) ao revisarem e historicizarem estudos dessa natureza. Esses autores expõem que os autores identificados, mapearam o ambiente utilizando-se de mais de uma medida. Por exemplo: (i) March e Simon (1958) com a avaliação dos recursos nominados como munificência; (ii) Emery e Trist (1965) com a complexidade e rotina e a instabilidade; (iii) Thompson (1967), a heterogeneidade e dinamismo; (iv) Child (1972), a complexidade e estabilidade; (v) Mintzberg (1979), a complexidade e diversidade e a estabilidade; (vi) Aldrich (1979), a concentração e heterogeneidade, estabilidade e turbulência, e capacidade de consenso; (vii) Tung (1979), a complexidade e rotina, e instabilidade; (viii) Dess e Beard (1984), a complexidade, dinamismo e a munificência. Intentam-se sobre os oito grupos com as respectivas denominações dadas ao ambiente, que o assunto rompeu décadas com suas distintas denominações, mas, com a ótica voltada para a mensuração do ambiente organizacional. No Quadro 2, pode ser observado os principais conceitos utilizados para relatar as características do ambiente geral na organização. 


\begin{tabular}{|c|c|c|c|}
\hline $\begin{array}{c}\text { PrinciPaIS } \\
\text { TRABALHOS } \\
\text { SOBRE AMBIENTE } \\
\text { ORGANIZACIONAL }\end{array}$ & COMPLEXIDADE & $\begin{array}{l}\text { DINAMISMO E } \\
\text { EsTABILIDADE }\end{array}$ & $\begin{array}{c}\text { DisPONI- } \\
\text { BILIADE DE } \\
\text { RECURSO }\end{array}$ \\
\hline $\begin{array}{l}\text { March e Simon } \\
\text { (1958) }\end{array}$ & - & - & Munificência \\
\hline $\begin{array}{l}\text { Emery e Trist } \\
\text { (1965) }\end{array}$ & $\begin{array}{l}\text { Complexidade } \\
\text { Rotineirização }\end{array}$ & Instabilidade & - \\
\hline $\begin{array}{l}\text { Thompson } \\
\text { (1967) }\end{array}$ & $\begin{array}{l}\text { Heteroge- } \\
\text { neidade }\end{array}$ & Dinamismo & - \\
\hline Child (1972) & Complexidade & Estabilidade & - \\
\hline $\begin{array}{l}\text { Mintzberg } \\
\text { (1979) }\end{array}$ & $\begin{array}{l}\text { Complexidade } \\
\text { e Diversidade }\end{array}$ & Estabilidade & Hostilidade \\
\hline Aldrich (1979) & $\begin{array}{c}\text { Concentração/ } \\
\text { Heteroge- } \\
\text { neidade }\end{array}$ & Turbulência & $\begin{array}{l}\text { Capacidade } \\
\text { de Consenso }\end{array}$ \\
\hline Tung (1979) & $\begin{array}{l}\text { Complexidade } \\
\text { Rotineirização }\end{array}$ & Instabilidade & - \\
\hline $\begin{array}{l}\text { Dess e Beard } \\
\text { (1984) }\end{array}$ & Complexidade & Dinamismo & Munificência \\
\hline
\end{tabular}

Quadro 2: Características do Ambiente

Fonte: Adaptado de Sharfman e Dean (1991)

Sob esse enfoque, Thompson (1967) assevera que, se o gestor não dispuser de informações concretas sobre determinado ambiente, isso fará que se aumentem os efeitos de ações organizacionais específicas da certeza, a partir do risco à incerteza na tomada de decisão. A complexidade ambiental refere-se à diversidade $e$ a heterogeneidade das atividades essenciais da organização. Nos achados de Dess e Beard (1984), o ambiente dinâmico ou dinamismo ambiental está relacionado ao problema de se presumir o futuro em vistas as mudanças imprevisíveis que ocorre em um dado ambiente. Assim, a complexidade de um ambiente será maior quanto maior for o número de fatores no ambiente percebido pelos gestores e quanto maior forem as diferenças entre esses fatores. (DESS; BEARD, 1984). Há a necessidade de um amplo envolvimento de relacionamentos em ambiente complexo exigindo um elevado grau de abstração para produzir planejamentos gerenciais. (BATAGLIA, 2005)

Já o ambiente munificente se caracteriza como aquele capaz de suportar a operação e o desenvolvimento sustentável da organização, associado ao grau de abundância ou escassez dos recursos. Porém, pesquisas evidenciam que a formação $e$ o desen- volvimento de relações interorganizacionais têm se mostrado inversamente relacionados com elevadas taxas de munificência (ALDRICH, 1979). Nos escritos desses autores, eles argumentam que os estudos de Sharfman e Dean Jr. (1991) oferecem uma visão geral e organizada da literatura das principais pesquisas e sua dimensão do ambiente de negócio até 1991, ou ainda, ao longo dos últimos 30 anos (1958-1984). O assunto foi retomado por Rueda-Manzanares, Aragón-Correa e Sharma (2008), que denotam ter havido um grande progresso em âmbito teórico a respeito das dimensões do ambiente organizacional. Porém, ressalta-se que a operacionalização dessas dimensões foi adotada por Dess e Beard (1984) a partir do agrupamento das dimensões ambientais estabelecidas por Aldrich (1979), os quais as reduziram por meio de técnica estatística de análise fatorial exploratória a três variáveis importantes denominadas de: munificência, complexidade e dinamismo. E, a partir de então, essas variáveis têm sido usadas para examinar a influência do ambiente geral nas organizações.

\section{Métodos e Procedimentos da Pesquisa}

A presente pesquisa constitui um estudo de caso, desenvolvido na Cooperativa de Crédito (Viacredi) com sede em Blumenau/SC, identificada pelo seu grau de representatividade no setor em que atua e pela disponibilidade para participação na pesquisa. Triviños (1987) considera o estudo de caso um tipo de pesquisa cujo objeto é uma unidade que se analisa profundamente. $\mathrm{O}$ critério de escolha teve como fundamento, a definição dada por Yin (2001), ou seja, pela lógica de replicação, podendo ser classificada como literal, isto é, a busca de resultados semelhantes, ou ainda replicação teórica, pela busca de resultados contrários. Os procedimentos metodológicos da pesquisa implicaram em: (i) análise descritiva dos dados levantados; (ii) e análise de dados qualitativos. A investigação foi também ex-post-factum (VERGARA, 1998). O estudo teve avaliação de corte transversal (RICHARDSON, 1999), o nível da análise foi organizacional, e a unidade de análise e os níveis estratégico (Presidente), tático e operacional tiveram o intuito de obter a triangulação dos dados. 
O estudo buscou analisar a percepção dos gerentes da cooperativa de crédito antes e durante a implantação do planejamento estratégico, assim como a relação entre as estratégias de influência dos stakeholders, sua capacidade de administração dos stakeholders o ambiente munificente. A dimensão analítica teve ainda o uso das teorias desenvolvidas por Freeman (1984), com uso da metodologia para mapear os stakeholders; Frooman (1999) utilizou para analisar as estratégias de influência dos stakeholders quanto ao grau de dependência entre a empresa e seus stakeholders; e para mensurar a munificência do ambiente foi utilizado os preceitos de Castrogiovanni (1991) quanto à abundância e à escassez de recursos.

Em âmbitos gerais, a operacionalização para a realização deste estudo foi: (i) levantamento e identificação dos stakeholders primários e secundários envolvidos no processo para a implantação do planejamento estratégico com informações sobre o perfil profissional dos entrevistados; (ii) realização de entrevistas; (iii) análise da dimensão do ambiente munificente; (iv) identificação da tipologia das relações de recurso $e$ estratégias, e da influência dos stakeholders; (v) análise da capacidade de administração dos stakeholders em relação ao ambiente organizacional, na percepção do gestor da cooperativa em questão.

As entrevistas ocorreram com três funcionários no total, quais sejam: um profissional em nível estratégico, o diretor da cooperativa, um profissional em nível tático, responsável por toda área de Gestão de Pessoas; e, um profissional em nível operacional, operador de caixa. Além disso, foi efetuado um survey com os 14 Coordenadores de cada Unidade da Viacredi (Quadro 3) de Blumenau/SC.

Conforme a metodologia de Freeman (1999) e Clarkson (1995), houve o mapeamento dos stakeholders primários (acionistas, investidores, proprietários, conselho de administração e funcionários) e secundários (sindicato, competidores, fornecedores, grupos governamentais e clientes). Contudo, para fins de melhor unicidade do trabalho foram considerados como Stakeholders da Viacredi: Agentes Financeiros, Ambientalistas, Comunidade Local (lideranças), Concorrentes, Cooperados, Fornecedores, Funcionários, Governo, Grupos de defesa do consumidor, e Órgãos de imprensa. A partir das entrevistas realizadas com os diretores, se questionou, diante da relação dos

\begin{tabular}{|c|c|c|}
\hline ENTREVISTADO & Овлеtivo & $\begin{array}{c}\text { DuRAÇÃo DA } \\
\text { ENTREVISTA }\end{array}$ \\
\hline $\begin{array}{l}\text { Diretoria } \\
\text { Administrativa } \\
\text { (Nível } \\
\text { Estratégico) }\end{array}$ & $\begin{array}{l}\text { Coletar dados primários: } \\
\text { Identificar categorias } \\
\text { de stakeholders para a } \\
\text { implantação do PE. }\end{array}$ & 1h10 minutos \\
\hline $\begin{array}{l}\text { Gerente RH } \\
\text { (Nível Tático) }\end{array}$ & $\begin{array}{l}\text { Coletar dados primários: } \\
\text { Identificar percepção } \\
\text { do nível tático sobre a } \\
\text { influência dos stakeholders } \\
\text { em consonância com ao } \\
\text { ambiente organizacional em } \\
\text { relação ao PE da ViaCredi. }\end{array}$ & 40 minutos \\
\hline $\begin{array}{l}\text { Op. Caixa } \\
\text { (Nível } \\
\text { Operacional) }\end{array}$ & $\begin{array}{l}\text { Coletar dados primários: } \\
\text { Identificar percepção do } \\
\text { nível operacional sobre a } \\
\text { influência dos stakeholders } \\
\text { em consonância com ao } \\
\text { ambiente organizacional em } \\
\text { relação ao PE da ViaCredi. }\end{array}$ & 20 minutos \\
\hline
\end{tabular}

Quadro 3: Ambiente da organização e seus Stakeholders Fonte: Elaborado pelos autores deste artigo (informações foram coletadas em julho de 2010)

stakeholders primários e secundários, quais foram os stakeholders considerados antes e durante a implantação do Planejamento Estratégico da empresa, a partir de questionário com escala likert com intensidade de 5 pontos, sendo a classificação para 1 (o mais baixo) a 5 (o mais alto). Foram considerados aqueles stakeholders que apresentaram mais de $50 \%$ das respostas da metade da escala (3) para cima (PROCOPIAK, HOFFMANN, ROSSETTO, 2007). Em seguida, na mesma entrevista e com uso das tipologias de Frooman (1999), foi verificado quanto as estratégias de influência que os stakeholders podem adotar, ou ainda, sobre o grau de dependência (recursos) entre a organização e seus stakeholders. Especificamente questionou-se se, para cada stakeholder (mapeado) a organização é dependente dos interesses dos stakeholders; ou os stakeholders são dependentes dos interesses da organização; e quando os interesses entre organização $e$ stakeholders são recíprocos quanto ao grau de dependência. Dessa forma, para os resultados obtidos nessa investigação seguiu-se ainda Frooman (1999) quanto à verificação sobre os interesses entre a organização e os stakeholders.

Para medir o grau de capacidade de gerenciamento dos stakeholders pela Viacredi foram utilizadas 
as três perspectivas propostas por Freeman (1984): racional, processo e transacional. Para cada perspectiva foi necessário: (a) descrever o nível racional que está associado a quais são os stakeholders da organização - mapear os stakeholders (primários e secundários); (b) descrever o processo organizacional (ações estratégicas - Planejamento Estratégico) quanto ao gerenciamento das relações com os seus stakeholders; (c) descrever o nível transacional quanto ao conjunto de operações entre a organização e os seus stakeholders, e se essas operações ou negociações se ajustam com o mapa dos stakeholders.

\section{Caracterização da Cooperativa}

A Cooperativa de crédito Vale do Itajaí é uma instituição financeira, organizada sob a forma de sociedade cooperativa e fiscalizada pelo Banco do Brasil. Fundada em 26 de novembro de 1951 por 21 funcionários da Companhia Hering, que inspirados nos moldes da Cooperativa de Crédito das Indústrias Renner, no Rio Grande do Sul, criaram a Viacredi, na época, denominada Credihering. Constituída sob o segmento Luzzatti, possui como filosofia oportunizar opções de poupança e ao mesmo tempo, crédito de forma mais acessível e simples, como, também, forte motivação para facilitar aos cooperados a compra da casa própria. Inicialmente teve como área de atuação o município de Blumenau. Entretanto, na década de 1960 ampliou seu atendimento, admitindo desde então, como cooperados, os funcionários que atuavam nas filiais da Companhia Hering. Essas filiais ficavam localizadas em cidades vizinhas, abrindo postos de atendimento nestes municípios a partir da década de 1980. Em novembro de 2001, a maioria dos cooperados elegeu o nome Viacredi como nova designação para a Credihering. Em março, do mesmo ano, a assembleia geral homologou o nome, Cooperativa de Crédito Vale do Itajaí (Viacredi), sendo aprovado pelo Banco Central do Brasil no final de abril de 2002, e passou também a adotar desde então, um novo símbolo. A Cooperativa atualmente tem mais de $120 \mathrm{mil}$ cooperados (março/2010), em benefício dos quais, promove o desenvolvimento econômico e social, a partir da prestação de serviços financeiros, com qualidade, custos baixos e, orientada pelos princípios cooperati- vistas. Na Viacredi, os cooperados têm a oportunidade de participar sempre, seja nas operações realizadas no dia a dia, contribuindo com sugestões ou por meio de assembleias gerais. Atualmente são 46 Postos de Atendimento, presentes nos municípios de Blumenau, Apiúna, Ascurra, Gaspar, Ibirama, Ilhota, Indaial, Itajaí, Jaraguá do Sul, Massaranduba, Presidente Getúlio, Rio dos Cedros, Rodeio, Timbó e Guabiruba. A matriz integra um sistema de cooperativas de crédito constituído há 60 anos na região de Blumenau e conta com mais de 149 mil cooperados (fevereiro/2010). Atualmente, a Cooperativa Central de Crédito Urbano (CECRED) possui 13 filiadas: Viacredi, Creditêxtil, Concredi, Cecrisacred, Credifiesc, Credcrea, Credelesc, Transpocred, Credifoz, Credicomin, Rodocrédito, SCRcred e Crevisc, com atuação em Anápolis, Apiúna, Ascurra, Balneário Camboriú, Blumenau, Brusque, Camboriú, Chapecó, Criciúma, Florianópolis, Francisco Beltrão, Gaspar, Guabiruba, Guaramirim, Ibirama, Ilhota, Indaial, Itajaí, Jaraguá do Sul, Joinville, Massaranduba, Navegantes, Penha, Pomerode, Presidente Getúlio, Rio do Sul, Rio dos Cedros, Rodeio, Santa Luzia, São Bento do Sul, Timbó e Tubarão. A Viacredi, anualmente, desenvolve pesquisa de satisfação com os cooperados, a partir de três indicadores: atendimento, produtos e serviços e avaliação do Progrid. Os dados da pesquisa de 2010 demonstram que a média das notas estipuladas para os Postos de atendimento foi de 9,5. Outro indicador analisado na pesquisa foi: oferecer ao cooperado produtos e serviços que ele precisa, obteve um índice de 9,1. Outro índice foi: Avaliação do Programa de Integração e Desenvolvimento de Cooperados, que obteve uma média de 9,3. Sobre esse cenário é possível fazer uma analogia da visão de Donaldson e Preston (1995) sobre as três dimensões: descritivo/empírica, instrumental $e$ normativa. Tem-se, com a primeira dimensão, a pessoa do dirigente geral, pois reflete o nível estratégico nas características do comportamento organizacional, na natureza da empresa em suas estratégias de gestão. $\mathrm{Na}$ segunda dimensão está a relação entre os stakeholders e os objetivos da organização e, isso, pode ser encontrado nos sete princípios cooperativistas da Viacredi: (i) adesão voluntária e livre; (ii) gestão democrática pelos membros; (iii) participação econômica dos membros; (iv) autonomia e independência; (v) educação, formação e informação; (vi) intercooperação; (vii) interesse pela comunidade. A terceira dimensão 
age na interpretação da função da organização, e está presente no nível operacional, da forma como atua com os diversos stakeholders.

\section{Resultados}

Os resultados foram divididos de acordo com a classificação aplicada na pesquisa, quais sejam: (1) o grau de importância dos stakeholders na tomada de decisão; (2) classificação do ambiente organizacional (ambiente de negócios); (3) capacidade e processo; (4) influencia dos stakeholders no ambiente da organização; (5) classificação dos processos organizacionais.

\subsection{O Grau de Importância dos Stakeholders na Tomada de Decisão}

Para o resultado 1, o grau de importância dos stakeholders na tomada de decisão tem-se que o estudo empírico semelhante foi adotado por Procopiak, Hoffmann e Rossetto (2007), identificando a intensidade de cada stakeholder. Os autores classificaram em uma escala de 5 pontos em ordem de menor para maior importância os stakeholders primários, seriam os que obtivessem representatividade acima de 50\% das respostas da escala. O presente artigo partiu para uma análise semelhante, entretanto, com inversão das categorias da escala e considerando stakeholders primários os que obtiveram média abaixo de dois.

Ainda, sobre o comentário da CMCC (2010), notoriamente, os resultados da pesquisa que os stakeholders considerados primários na percepção dos coordenadores são em primeiro lugar a comunidade local $(1,0)$, seguido dos cooperados $(1,2)$, funcionários $(1,4)$, agentes financeiros $(1,5)$ e governo $(1,6)$. Clarckson (1995) classifica os stakeholders entre primários e secundários. Os primários são aqueles em que sem a presença deles a organização não conseguiria sobreviver e os secundários que influenciam ou são influenciados pela organização. Reforça-se o comentário do CMCC (2010) em que servem os seus membros e comunidades e diferencia-se dos Bancos principalmente pela sua estrutura, ou ainda, não possui fins lucrativos. Todavia, no que tange aos concorrentes, ficou evidenciado pelo nível estratégico em entrevista realizada, que os bancos, apesar de terem outra característica (fins lucrativos), também devem ser considerados concorrentes, pois, movimentam seu patrimônio monetário em outra instituição financeira. Além disso, o dirigente informa que os estabelecimentos comerciais que oferecem facilidades de pagamentos também devem ser considerados concorrentes. Isso se reflete no comentário feito pelo dirigente: "[...] um cliente não utilizar nosso crédito para adquirir um produto, já deve ser considerado concorrente". No nível tático, percebeu-se que os bancos também são considerados concorrentes, mas, "[...] não tão diretos, já que o sistema adotado pela cooperativa seja outro".

O que pode ser comprovado nas respectivas falas dos níveis estratégico, tático e operacional é que o planejamento estratégico permeia por diversas funções, ou seja: (a) nível estratégico "[...] todas nossas ações são direcionadas para a comunidade e para isso mantemos relacionamento com formadores de opinião dos bairros"; (b) no nível tático "[...] todas as nossas diretrizes e ações são repassadas aos coordenadores que, por sua vez, repassam ao nível operacional"; e (c) no nível operacional "[...] atendemos a toda comunidade, pois não só cooperados utilizam nossos serviços". Identificou-se que os órgãos de imprensa, grupos de defesa do consumidor, fornecedor e ambientalistas foram considerados os stakeholders com menos importância. De alguma forma, eles não interferem diretamente, mas são importantes também para uma análise do ambiente no momento de decisão estratégica.

\subsection{Classificação do Ambiente Organizacional (Ambiente de Negócios)}

No resultado 2 há a classificação do ambiente organizacional (ambiente de negócios). Para classificação do ambiente, foram adotadas 06 categorias em escala likert de grau de concordância de 1 para discordo totalmente até 5 para concordo totalmente. Ao se ter como categorias os fatores que afetam o ambiente de negócios da cooperativa (e.g. a regulamentação, operações de crédito, taxação, cooperados, etc.) mudam muito frequentemente e as mudanças ocorridas no ambiente de negócios da cooperativa são facilmente previsíveis, na percepção dos coordenadores não se percebe alta variação sobre os fatores do ambiente no negócio da cooperativa. Essa situação poderia 
classificar o ambiente como simples em um ambiente que não possui condições ambientais e a percepção de incerteza, conforme Duncan (1972). Entretanto, percebe-se, no comentário do dirigente geral, que o monitoramento é constante sobre as regulamentações, operações de crédito, taxação, cooperados, qual seja: "Todos os dias os números são avaliados na Viacredi e acompanhamento mudanças advindas do Banco Central". Esse cenário se preconiza por Lawrence e Lorsch (1967) e Duncan (1972) na incerteza para tomada de decisão e que é preciso considerar o ambiente em termos das informações que são fontes de recursos (PFEFFER; SALANCIK, 1978). Infere-se que essa certeza dos coordenadores seja explicada pelo comentário do nível tático: "A Viacredi preza pela transparência das suas ações com seus sócios disponibilizando materiais informativos e pesquisas informais dos coordenadores com os cooperados".

Sobre a terceira categoria a cooperativa não dispõe de recursos suficientes para desenvolver respostas competitivas aos desafios do ambiente, percebe-se uma discordância por parte dos coordenadores para atuar sobre o ambiente. Nesse sentido, percebe-se que o ambiente da Viacredi possui a munificência em termos de abundância de recursos, ao encontro do que justificam March e Simon (1958), Aldrich (1979) e Dess e Beard (1984) e Castrogiovanni (1991).

Quanto à quarta categoria é muito difícil saber claramente as consequências na atividade das nossas próprias decisões gerenciais, há fundamentos em Sharfman e Dean Jr. (1991) sobre a incerteza na tomada de decisão; e pelas respostas obtidas dos coordenadores percebeu-se uma diferença entre aqueles que acreditam saber ou não claramente as consequências de suas decisões gerenciais. Ao buscar suporte na entrevista, verificou-se no comentário do nível estratégico e tático, respectivamente o seguinte: "Temos controle parcial das nossas ações. Sempre verificamos o reflexo das nossas ações na comunidade, mas não existe nada formalizado [...]" e "Existem controles internos em geral sobre as metas não só em termos de produtos, mas a nível de satisfação. Todo ano é feita uma pesquisa com os cooperados e recentemente foi realizada uma pesquisa de clima organizacional".

A quinta categoria antes de iniciar a construção da decisão é preciso entender claramente os grupos, pessoas e interesses envolvidos no processo, reflete-se sobre o contexto da complexidade preconizada por Dess e Beard (1984). Enquadram-se aspectos dos preceitos teóricos de heterogeneidade e concentração geográfica de Aldrich (1979), visto ter um total de 18 cooperativas em Blumenau, mais de 140.000 (cento e quarenta mil associados). O resultado da pesquisa aponta que a diversidade de stakeholders demonstra o quão complexo pode ser o ambiente. Conforme já mencionado anteriormente, a Viacredi atua a partir de indicadores financeiros, inseridos neles, os stakeholders de instituições financeiras, governo e mídia. Outro indicador utilizado é a pesquisa de satisfação dos cooperados, votações em assembleias e "[...] relacionamento com formadores de opinião como representantes religiosos e, diretores de escolas" (Dirigente Geral). Cabe aqui o comentário de Weick (1979) sobre o interacionismo simbólico em que o ambiente é determinado a partir das percepções de seus gestores. O contexto da Cooperativa é um pouco diferente, já que podem ser considerados como gestores, os próprios associados conforme comentário do nível tático "[...] apesar dos colaboradores atuarem no processo da cooperativa quem gere a organização são os próprios associados que interagem e decidem pelas ações da cooperativa em consenso em assembleia". Ou ainda, o mesmo stakeholder pode exercer diversos papéis ao mesmo tempo.

A sexta categoria, a informação necessária para tomada de uma decisão estratégica sempre está disponível em um plano único e bem estruturado, possui resultado divergente entre coordenadores e os níveis estratégico e tático. Os coordenadores não percebem as decisões estratégicas estruturadas em um plano formal, enquanto na entrevista, os dirigentes apontaram que há um planejamento formalizado que é seguido e retomado para as estratégias da cooperativa. "O planejamento é formal" e encontra-se disponível no próprio sítio da Viacredi. Talvez, seja possível inferir aqui que o ambiente da cooperativa seja dinâmico (THOMPSON, 1967; DESS; BEARD, 1984), o que poderia prejudicar a formalização de processos estratégicos, o que resulta em incerteza sobre as ações do nível operacional que comenta "[...] as ações são passadas via reunião semanalmente, com informações sobre a cooperativa em geral e sobre as metas de cada Pac" - Posto de atendimento a cooperados (PAC). Aspecto esse convergente com a concepção de Dess e 
Beard (1984) sobre o dinamismo ambiental ser fator dificultador para presumir o futuro em virtude das imprevisibilidades de determinado ambiente.

\subsection{Capacidade e Processo}

Ao resultado 3 sobre a capacidade e processo foram expostas em cada categoria duas situações na que os coordenadores deveriam se posicionar mais próximos a uma ou a outra também a partir de uma escala de 5 pontos. A primeira implicação obtida com uma média de 2,8 para a categoria nossos produtose serviços são poucos e muito semelhantes. Nossas atividades estão intimamente relacionadas com aspectos para o desenvolvimento econômico e social dos cooperados e comunidade demonstra uma estabilidade por parte dos recursos da organização e caraterizá-los como simples, ou seja, sem muita variação. O que pode gerar maiores fatores de certeza. Contudo, a certeza nas ações não permeira apenas os recursos da organização, mas também o ambiente em que ela se encontra, o que pode gerar incertezas. Outro resultado refere-se à: principal preocupação da cooperativa diz respeito a melhor alternativa em soluções financeiras com menores taxas de juros ao mesmo tempo em que se oferece um serviço de qualidade com uma média de 1,3. Demonstrando pouco interesse sobre os processos em termos de produtividade. Apesar de ter apresentado indicadores com altos scores na pesquisa de satisfação dos cooperados, a gestora do $\mathrm{RH}$ (nível tático) comenta que "[...] o foco é fornecer facilidades para o cooperado e, que aliado a isso, vem a excelência na prestação do serviço". Acredita-se que a não posição de nenhum coordenador sobre $A$ principal preocupação da cooperativa se refere a criar avaliação de produtividade com tecnologias flexíveis e inovadoras seja encontrada no comentário do dirigente geral em que "uma das nossas deficiências é a integração bancária por meio de determinados sistemas que são muito caros, mas que aos poucos vão evoluindo, como é o caso das compensasões que agora conseguem fazer na hora".

\subsection{Influência dos Stakeholders no Ambiente da Organização}

No resultado 4, para a influência dos stakeholders no ambiente da organização, é possível fazer referência aos estudos de Mitchell, Agle e Wood (1995), quando eles classificam os stakeholders com base nos atributos poder, legitimidade e urgência. O atributo poder está na capacidade de um stakeholder influenciar a organização. Nesse sentido, de acordo com a percepção dos coordenadores dos Pacs, é possível identificar que os stakeholders que possuíram maiores indicadores de poder no sentido de atenção prestada pelo agente de forma geral são a comunidade local, os cooperados $e$ os agentes financeiros. Em relação à legitimidade, ela está ligada às normas, aos valores e às definições nos indivíduos organização e sociedade. E a urgência está sobre o grau com que os stakeholders reinvidicam atenção. De acordo com o dirigente geral "[...] todas as deliberações sobre as ações da cooperativa devem ser transparentes e aprovadas em assembleias [...]", a gestora do $\mathrm{RH}$ comentou que "[...] são realizadas reuniões semanais com os Coordenadores e Pac's e seus respectivos colaboradores em nível operacional".

Ao continuar sob o mesmo enfoque analítico, e seguindo os preceitos de Frooman (1999), há quatro tipos de estratégias na relação influência dos stakeholders, mais especificamente, retenção direta e indireta e, uso direto e indireto. Um esboço foi demonstrado no Quadro 1. O estudo de Procopiak, Hoffmann e Rossetto (2007) também teve base nos preceitos de Frooman (1999). Em uma relação das médias obtidas, percebe-se que o agente que possui maior dependência da organização é o concorrente e fornecedor. Isso se justifica no primeiro caso pela "Viacredi tem baixas taxas de juros em comparação com as demais insitituições financeiras, mas o valor para resgate geralmente é baixo" (SIC - dirigente geral) e, pelo fornecedor na qual a Viacredi possui poder de barganha pelo fato de que neste momento é cliente. Em relação aos outros agentes, percebe-se índices altos tanto de dependência por parte da organização quanto dos stakeholders enquadrando-os na dimensão uso direto, ou seja, alta interdependência. Outro fator é se a cooperativa estabelece um sistema de planejamento bastante rigoroso $e$ detalhado. Nesse caso, a média foi de 2,6, justificando no comentário da gestora de $\mathrm{RH}$ (nível tático) de que "[...] as reuniões são constantes, semanalmente, $e$ os coordenadores recebem instruções e normativas por escrito de novos procedimentos e metas a serem atingidas". 
No que tange à cooperativa dispõe de um manual de procedimentos que identifica e avalia a existência de fatores internos e externos que possam afetar adversamente a realização dos objetivos da coorperativa, esse tema obteve média 1,9, caracterizando uma formalidade na busca por informações. Ademais, o dirigente geral relata que "[...] mesmo o monitoramento sendo constante, não manual de procedimentos que avalie o ambiente organizacional sobre as informações externas à cooperativa". Acredita-se que a diferença de opiniões seja pelo fato de que os coordenadores recebem instruções formais, enquanto o nível estratégico avalia o ambiente a partir de diversas ferramentas, sem necessariamente serem padronizadas. Infere-se que foi unânime o posicionamento pela categoria a cooperativa dispõe de relatórios gerenciais de avaliação da qualidade e adequação dos controles internos (média 1,0). Isso, porque na fala do dirigente houve o destaque para "[...] há preocupação com patrimônio do associado".

\subsection{Classificação dos Processos Organizacionais}

No resultado 5 , referente à classificação dos processos organizacionais, foram indicadas 27 situações nas quais os coordenadores deveriam identificar o grau de concordância, sendo 1 para discordo totalmente e 5 para concordo totalmente. Foram consideradas relevantes as médias acima de 4 pontos. O primeiro atributo refere-se à busca pela educação cooperativista e capacitação profissional. Nesse quesito foram unânimes os coordenadores em afirmar que concordam pelo processo que é realizado. Isso se reflete nos cursos de integração para novos sócios, cursos de capacitação advindos do PROGRID, conforme comentado anteriormente, além de que "[...] são oferecidos cursos e treinamentos constantemente para os funcionários. Os coordenadores são capacitados e se tornam multiplicadores de procedimentos em cada Pac" - fala da gerente $\mathrm{RH}$ (nível tático).

Unanimidade também ocorreu sobre ter uma rentabilidade a longo prazo dos investimentos realizados. A média 5 se justifica pela própria situação de mercado pelo crescimento da coorperativa em número de postos de atendimento, cooperados e funcionários. Conforme a gerente do $\mathrm{RH}$ (nível tático) "[...] as capacitações são constantes, pois toda semana entram novos colaboradores, visto o tamanho crescimento que a cooperativa possui". Já, segundo o dirigente geral, "[...] há dinheiro em caixa para crédito, mas poucos vem realizando".

De acordo com a influência dos stakeholders e sua classificação entre os primários e o secundário, reafirmou-se aqui com média 5,0 e 4,9 para atenção prestada a famílias dos cooperados e atenção prestada para atender as demandas dos cooperados. A fala do nível operacional converge com o nível estratégico sobre o comentário de que "[...] a Viacredi é um ambiente familiar". O nível tático comenta que "[...] existe um departamento específico que trata dos cursos oferecidos pelo PROGRID e divulgação dos conselhos educacionais, formados por membros da própria comunidade [...]". Também foi bem avaliado, com uma média de 4,4 o indicador criar e promover uma cultura da inovação. Essa realidade é exposta no comentário do nível operacional em que "[...] são feitos encontros durante e fora do expediente para integração e troca de ideias". Outro ponto se destina a desenvolver objetivos gerais em metas específicas, com um score de 4,9, quase 5,0. Outra situação se dá pela busca de novas perspectivas para resolução de problemas, com uma média de 4,4. Esse indicador se reflete no comentário do nível operacional em que "[...] sempre somos questionados a dar nossas opiniões e novas ideias para melhorias no serviço [...]" - continua - "[...] somos ouvidos e nossas ideias são colocadas para a gerência que analisa o teor das mesmas". Em reforço tem-se o comentário do nível tático em que "[...] o feedback é dado ao coordenador, que repassa aos demais colaboradores". Considerando ainda a complexidade e a munificência do ambiente, é possível perceber que com uma média de 4,5, os coordenadores consideram-se capazes de agir e identificar oportunidades em situações de crise. Ainda sobre a ação, com médias 4,4; 4,6 e 4,4, respectivamente, realizam melhorias contínuas nos processos e sistemas; agir antes das outras cooperativas com novos produtos, serviços e sistemas e capacidade para gerar soluções flexíveis e baixo custo com problemas do ambiente organizacional. Segundo o dirigente geral (nível estratégico) "[...] isto é possível devido a quantidade de cooperados e abrangência que a cooperativa possui [...]" e, ainda reforça "[...] um dos nossos princípios é a intercooperação, e a nossa cooperativa estimula a filosofia cooperativista para que outras pessoas se 
associem a outras cooperativas". Faz-se importante ressaltar a média de 4,4 dada para atenção especial ao assunto relacionado ao meio ambiente (cuidados com a preservação), já que os ambientalistas não foram considerados stakeholders primários. No entanto, há de se considerar que essa preocupação não necessariamente está ligada aos ambientalistas, mas sim em uma ideia de sustentabilidade. Mesmo os funcionários e cooperados sendo percebidos como stakeholders primários houve baixo índice de 2,4 sobre incentivos e prêmios para funcionários e cooperados. Situação adversa ocorreu no comentário do nível operacional em que a partir das "metas atingidas são realizadas premiações do tipo brinde como chocolates a até dias de folga. Seria interessante também que envolvesse prêmio em dinheiro".

\section{Considerações Finais}

O presente artigo reflete acerca da influência dos stakeholders no ambiente estratégico da Cooperativa de Crédito Viacredi e considera suas relações com efeitos moderadores da munificência e, a capacidade da cooperativa gerir esses stakeholders. Para tanto, foi realizada uma pesquisa qualitativa com três entrevistas, respectivamente, com um funcionário em nível estratégico, um em nível tático e outro em nível operacional. A Cooperativa de Crédito Viacredi iniciou suas atividades com um total de 21 funcionários em 1951 e em 2011, conta com mais de 140 mil associados. Nesse sentido, a pesquisa avançou para classificação e influência dos stakeholders, capacidade e processo de gestão, classificação do ambiente e dos processos organizacionais.

Tendo como base o planejamento estratégico da organização, as ações permeiam os campos, mercadológico, econômico-financeiro, desenvolvimento econômico e social, processos internos, patrimônio humano e cultura organizacional, na percepção de seus dirigentes. No que diz respeito ao campo mercadológico identificou-se que os stakeholders primários são os próprios cooperativistas, e como secundários os fornecedores. A influência por parte dos cooperados influencia, tanto quanto são influenciados pela cooperativa, tornando assim, uma relação de interdependência entre eles. $\mathrm{O}$ que não ocasionou demonstrativo semelhante em relação aos fornecedores, já que a cooperativa possui maior poder de influência sobre esse stakeholder. A situação aqui apresentada vem ao encontro dos estudos de Froomann (1999) sobre a estratégia de influência dos stakeholders quanto ao grau de dependência deles. No aspecto mercadológico também foi possível perceber que há uma preocupação por parte da cooperativa em analisar o mercado, inclusive com realização de pesquisas de satisfação. Para o campo econômico-financeiro, os agentes financeiros e outras entidades são considerados concorrentes na percepção do dirigente. Essa realidade torna-se relevante, porque, ao mesmo tempo em que uma instituição financeira ocupa lugar neste campo de análise, ela pode, também, ocupar a cadeira de concorrência no campo mercadológico. $\mathrm{O}$ ambiente organizacional da cooperativa permite essa troca e a inversão de papéis entre os diversos stakeholders. Ao mesmo tempo em que outra cooperativa de crédito pode ser uma ameaça, ela é, ao mesmo tempo, uma parceira para prover a intercooperação. Ainda sobre o campo econômico-financeiro, percebeu-se na fala do dirigente geral preocupação em manter atualizadas informações advindas do banco central e outras fontes sobre procedimentos que envolvem a cooperativa. Diante disso, o ambiente pode ser considerado complexo pelo número de stakeholders (ALDRICH, 1979) e munificente de recursos com abundantes informações (DESS; BEARD, 1984). O dinamismo que envolve todo esse ambiente gera incertezas sobre as ações da cooperativa, mas, também, de certa forma, consegue agir proativamente em virtude de sua participação de mercado. (THOMPSON, 1967)

Quanto ao campo desenvolvimento econômico e social, a Viacredi tem como stakeholders primários a sociedade. A atuação e sua capacidade de gerir esses stakeholders ocorrem em meio a cursos e devido à participação no relacionamento com membros formadores de opinião, no caso, líderes religiosos e educadores. As assembleias ocorrem para direcionar as atividades da cooperativa, com base nos princípios cooperativistas.

Sobre os processos internos, os stakeholders também considerados primários foram os funcionários, que ora podem também ser considerados no papel de cooperados e ou inclusive papel de sociedade. Foi possível identificar que os processos internos são formais e controlados, mas, que também provém o campo do patrimônio humano e cultural de práticas que estimulam a inovação para novas possibilidades de gestão, 
quer a partir de reuniões, capacitações, pesquisas de clima organizacional e ou de assembleias deliberativas.

Contudo, foi possível perceber, também, uma integração sobre a comunicação utilizada nos níveis estratégico, tático e operacional que se estabeleceram pela pesquisa de levantamento com os coordenadores dos Pacs. Foi possível perceber ainda, uma troca em relação aos papéis dos stakeholders envolvidos, bem como um cuidado que a organização possui em atender esses stakeholders por meio da transparência de suas ações e divulgação de resultados. O monitoramento do ambiente apesar de não ser tão formalizado em âmbito externo, pode ser considerado como abundante de recursos (CASTROGIOVANNI, 1991). Propõe-se que novos estudos sejam realizados ampliando o universo de cooperativas de crédito para identificar se a realidade encontrada na Viacredi pode ser generalizada no segmento de atuação. Outra sugestão é a de que possam ser realizados outros tratamentos estatísticos a fim de identificar novos dados e achados que complementem a realidade aqui apresentada.

\section{REFERÊNCIAS}

AGLE, B. R. et al. Toward superior stakeholder theory.

Business Ethics Quarterly, Charlottesville, v. 18, p. 153-190, 2008.

ALDRICH, H. E. Organizations and environments. Englewood Cliffs, NJ: Prentice-Hall, 1979.

BATAGLIA, W.; FRANKLIN, M. A.; CALDEIRA, A.; SILVA, A. A. Implicações das teorias ambientais para a administração estratégica. In: XXX Enc. da Associação Nacional dos Programas de Pós-graduação em Administração - ANPAD, Salvador, Anais... Salvador: ANPAD, 2006.

CASTROGIOVANNI, G. J. Environmental munificence: a theoretical assessment. Academy of Management Review, New York, v. 16, n. 3, p. 542-565, 1991.

CHANDLER, A. D. Strategy and Structure: chapters in the history of the american industrial enterprise. Cambridge: Massachusetts Institute of technology Press. 1962.
CHILD, J. Organization structure, environment, and performance. Sociology, London, v. 6, p. 12-27, 1972.

CLARKSON, M. B. E. A stakeholder framework for analyzing and evaluating corporate social performance. Academy of Management Review, New York: Jstor, v. 20, p. 92-117, jan. 1995.

DESS, G. G.; BEARD, D. W. Dimensions of organizational task environments. Administrative Science Quarterly, New York, v. 29, p. 52-73, 1984.

DONALDSON, T.; PRESTON, L. E. The stakeholder theory of the corporation: concepts, evidence, and implications. Academy of Management Review, 1995.

DUNCAN, R. B. Characteristics of organizational environments and perceived environmental uncertainty. Administrative Science Quarterly, New York, v. 17, n. 3, p. 313-327, 1972.

ELIAS, A. A; CAVANA, R. Y.; JACKSON, L. S. Stakeholder analisys for R\&D Project management. R\&D Management, Manchester, v. 32, n. 4, p. 301-310, 2002.

EMERY, F. E.; TRIST, E. L.The causal texture of organizational environments. Human Relations, London, v. 18, p. 21-32, 1965.

FERREIRA, M. A. M.; GONÇALVES, R. M. L.; BRAGA, M. J. Investigação do desempenho das cooperativas de crédito de Minas Gerais por meio da análise envoltória de dados (DEA ). Econ. aplic., São Paulo, v. 11, n. 3, p. $425-445$, jul.-set. 2007.

FREEMAN, R. E. Strategic management: a stakeholder approach. Boston: Pitman. 1984. Disponível em: <http:// www.corporate-ethics.org/pdf/Strategic_Management_A_ Stakeholder_Approach.pdf>. Acesso em: 20 set. 2009.

FROOMAN, J. Stakeholder influence strategies. Academy of Management Review, New York, v. 24, n. 2, Apr. 1999.

HALL, R. H. Organizations: structures, processes and out-comes. Englewood Cliffs: Prentice Hall, 1984.

HANNAN, M. T. ; FREEMAN, J. H. The population ecology of organizations. American Journal of Sociology, Hawthorn, v. 82, p. 929-964, 1977. 
PROCOPIAK FILHO, J. A.; HOFFMAN, V. E.;

ROSSETTO, C. R. As estratégias de influência dos stakeholders nas organizações da indústria da construção civil - Setor de Edificações em Balneário Camboriú - SC. In: Enc. de Est. em Est., 3, 2007, Recife, Anais... Recife: ANPAD, 2007.

LAWRENCE, P. R.; LORSH, J. W. As Empresas e o ambiente. Petrópolis: Vozes, 1967.

MARCH, J. G.; SIMON, H. A. Organizations. Nova Iorque: Willey, 1958.

. Teoria das Organizações. 5. ed. Rio de Janeiro: FGV (Instituto de Documentação Editora da Fundação Getúlio Vargas), 1981.

MINTZBERG, H. An emerging strategy of "direct" research. Administrative Science Quartely, New York, v. 24, p. 582-589, Dec. 1979.

MITCHELL, R. K.; AGLE, B. R.; WOOD, D. J. Toward a Theory of Stakeholder Identification and Salience: defining the Principle of Who and What Really Counts. Academy of Management Review, New York, v. 22, n. 4, p. 853-886, 1997.

\section{PFEFFER, J.; SALANCIK, G. The external control of} organizations: a resource dependence perspective. New York: Harper \& Row, 1978.

PHILLIPS, R.; FREEMAN, R. E.; WICKS, A. C. What stakeholder theory is not. Business Ethics Quarterly, Charlottesville, v. 13. Issue 4, p. 479-502, 2003.

RICHARDSON, R. J. et al. Pesquisa social: métodos e técnicas. 3. ed. São Paulo: Atlas, 1999.

RUEDA-MANZANARES, A.; ARÁGON-CORREA, J. A.; SHARMA, S. The influence of stakeholders on the environmental strategy of service firms: the moderating effects of complexity, uncertainty and munificence.

British Journal of Management, London, v. 19, p. 185-203, 2008.

SHARFMAN, M. P.; DEAN, JR. W. Conceptualizing and measuring organizational environment: a multidimensional approach. Journal of management, Germantown, v. 17, n. 4, p. 681-700, 1991.
SHROPSHIRE, C.; HILLMAN, A. J. A longitudinal study of significant change in stakeholder management. Business \& Society, London, v. 46, n. 1, March. p. 63-87, 2007.

\section{TRIVIÑOS, A. N. S. Introdução à pesquisa em} ciências sociais: a pesquisa qualitativa em educação. São Paulo: Atlas, 1987.

\section{VERGARA, S. C. Projetos e relatórios de pesquisa} em administração. São Paulo: Atlas, 1998.

WEICK, K. The social psychology of organizing. 2. ed. Boston: Addison-Wesly, 1979.

WOCCU. World Council of Credit Unions. statistical report. [2010]. Disponível em: <http://www.woccu.org/>. Acesso em: 21 jul. 2010.

YIN, R. K. Estudo de caso: planejamento e métodos. 3. ed. Porto Alegre: Bookman, 2005. 